\title{
Heterochromatin of maize chromosomes: structure and genetic effects
}

\author{
Margarida L.R. de Aguiar-Perecin ${ }^{l}$, Antonio Fluminhan ${ }^{1,2}$, Janay A. dos Santos-Serejo ${ }^{l}$, José R. Gardingo ${ }^{1,3}$, \\ Mônica R. Bertão ${ }^{1,4}$, Maria Juliana U. Decicol and Mateus Mondin ${ }^{l}$ \\ ${ }^{I}$ Departamento de Genética, ESALQ, Universidade de São Paulo, 13400-970 Piracicaba, SP, Brasil. \\ Send correspondence to M.L.R.A.P. E-mail:mlrapere@carpa.ciagri.usp.br \\ ${ }^{2}$ Universidade do Oeste Paulista, Rodovia Raposo Tavares, $k m$ 572, 19067-175 Presidente Prudente, SP, Brasil. \\ ${ }^{3}$ Universidade Estadual de Ponta Grossa-PR, Praça Santos Andrade S/N, 84010-790 Ponta Grossa, PR, Brasil. \\ ${ }^{4}$ Universidade Estadual de Santa Cruz, Rodovia Ilhéus-Itabuna, km 16, 45650-000 Ilhéus, BA, Brasil.
}

\section{CLASSES OF MAIZE HETEROCHROMATIN}

Maize (Zea mays L.) chromosomes were first characterized by McClintock (1929) from studies of the first pollen mitosis. Later, McClintock $(1930,1931,1933)$ found that pachytene chromosomes showed better morphological details for cytological studies. The pachytene chromosomes were identified on the basis of their length, centromere position, prominent chromomeres and heterochromatic knobs (Longley, 1938; Rhoades, 1955; McClintock et al., 1981). Other heterochromatic regions found in a number of different chromosome regions have also been described: heterochromatin adjacent to the centromeres, heterochromatin of the nucleolar organizer region (NOR), B chromosomes and the abnormal chromosome 10 (Rhoades, 1978).

The examination of chromosomes of several races of maize has revealed that the number, size and position of knobs are variable and that they are found in 23 locations on the ten maize chromosomes (McClintock, 1978a; McClintock et al., 1981).

The identification of mitotic chromosomes using conventional staining was described by Chen (1969) and Filion and Walden (1973), while C-banding procedures have shown the presence of stained distal bands in mitotic chromosomes (Hadlaczky and Kálmán, 1975; Ward, 1980; Aguiar-Perecin, 1985; Rayburn et al., 1985; Jewell and Islam-Faridi, 1994). Ward (1980) and Aguiar-Perecin (1985) described differential staining of the classes of maize heterochromatin: heavily stained bands on mitotic chromosomes correspond to knobs, while staining of centric heterochromatin is hardly observed in well-condensed metaphases. NOR-heterochromatin appears differentially stained but with a lower degree of staining than knobs. No differential staining was observed in B chromosomes, but Ward (1980) observed staining of the $\mathrm{B}$ centric heterochromatin. Furthermore, the analysis of C-banded mitotic metaphases of maize races with different knob constitutions showed that large bands corresponding to large and medium knobs alter the arm lengths of mitotic chromosomes (Aguiar-Perecin and Vosa, 1985).

The different classes of maize heterochromatin can also be differentiated by their times of replication in the mitotic cycle, for knobs replicate later than other hetero- chromatic regions (Pryor et al., 1980). Also, Peacock et al. (1981) found that a repeating unit of 180 base pairs is the major component of knob heterochromatin. A certain level of polymorphism has been detected among copies of this180-bp sequence (Dennis and Peacock, 1984),while Viotti et al. (1985) reported that this 180-bp repeat can be found at some euchromatic sites of pachytene chromosomes. A strict correspondence between the size of the Cbands and the signal for the in situ hybridization of the 180bp sequence has been observed along with new evidence of increase of arm length by large bands on metaphase chromosomes (Bertão, 1998).

The recovery of maize chromosome addition lines of oat (Avena sativa L.) from oat $\mathrm{x}$ maize crosses, each possessing an individual maize chromosome, has provided a unique opportunity to study knob DNA structure (Ananiev et al., 1998). The analysis of an oat-maize chromosome 9 addition line has revealed that blocks of tandemly arranged 180-bp repeating units are interrupted by insertions of other repeated DNA sequences, mostly represented by individual full-size copies of retrotransposable elements.

\section{GENETIC EFFECTS OF HETEROCHROMATIN OF MAIZE CHROMOSOMES}

Some genetic effects have been reported to be associated with the heterochromatin of B chromosomes, abnormal chromosome 10 , knobs and chromatin adjacent to the centromeres (Rhoades, 1978).

Among the effects caused by B chromosomes is the loss of terminal chromosomal segments from knobbed A chromosomes at the second microspore mitosis in spores possessing two or more $\mathrm{B}$ chromosomes (Rhoades and Dempsey, 1973). B chromosome nondisjunction also occurs at the second microspore division and Rhoades and Dempsey (1973) proposed a mechanism to explain both events by postulating that delayed replication of centric $B$ heterochromatin and knobs of A chromosomes results in $\mathrm{B}$ chromosome nondisjunction and formation of bridges as the two sister centromeres of A chromosomes move to opposite poles, resulting in the loss of segments of the A chromosomes. 
Some interesting effects have been associated with the large heterochromatic block of abnormal chromosome 10 (K10), including preferential segregation during megasporogenesis and neocentromere formation (Rhoades, 1978). Preferential segregation and neocentromere formation involve the interaction of K10 with knobs on other chromosomes at specific meiotic stages. Neocentromeres occur in homozygotes and heterozygotes for K10, but not in homozygotes for normal chromosome 10 , and are found on knobbed arms of chromosomes at anaphase I and anaphase II, where the distal neocentric regions undergo a precocious movement, pulling the ends of the chromosomes to the poles. Rhoades (1978) suggested that neocentromere formation accounts for preferential segregation: at the second meiotic division of megasporogenesis the basal spore preferentially receives a knobbed chromatid.

Studies of the variability of knob size and numbers among maize races have emphasized the importance of knowledge of knob contents in helping to understand problems associated with the origin of maize and its presentday races (McClintock, 1978a; McClintock et al., 1981). Knobs have also been associated with differences in recombination in particular regions of the chromosome complement (Rhoades, 1978). Chughtai and Steffensen (1987) reported a positive correlation between the presence of some knobs and later flowering time while AguiarPerecin, M.L.R. de (unpublished results) has observed that hybrids heterozygous for certain knobs are more precocious than the parents (inbred lines derived from a tropical variety) homozygous for the presence or absence of the same knobs.

\section{INVOLVEMENT OF KNOBS IN CHROMOSOME BREAKAGE IN MAIZE CALLUS CULTURES}

The development of tissue culture techniques has led to several investigations on the induction of chromosome aberrations resulting from alterations in the behavior of heterochromatic regions in cell cultures. This problem is particularly discussed in this article.

Several authors have described the occurrence of genetic and cytogenetic variation in plants regenerated in vitro. Although such variation, designated somaclonal variation by Larkin and Scrowcoft (1981), may be useful for crop improvement it is undesirable when genetic stability is required.

Changes in chromosome number and structure have been found in plants regenerated from tissue culture. Such changes can be induced by media components, culture age, explant tissue and genotype. Chromosome breakage and its consequences (deficiencies, duplications, translocations and inversions) are events quite frequently observed in plant tissue culture. Such breakpoints are often associated with late-replicating chromosome regions (reviewed by Peschke and Phillips, 1992). This was first described by Sacristan (1971) in Crepis capillaris callus cultures where rearrangements involving chromosome breaks at heterochro- matin were found. Since then, breakpoints involved in chromosome alterations associated with heterochromatic regions have been detected in regenerated plants from several species (McCoy et al., 1982; Lapitan et al., 1984; Johnson et al., 1987).

Meiotic studies of regenerated maize showed that most breakpoints are located between the centromere and knobs or the nucleolus organizer (Lee and Phillips, 1987). A hypothesis proposed to explain the role of heterochromatin in inducing chromosome breakage is that normally late-replicating heterochromatin may replicate even later in culture, leading to the formation of bridges due to delayed separation of sister chromatids at knob sites.

Variation of chromosome number has been reported in a few investigations of maize callus cultures (Edallo et al., 1981; McCoy and Phillips, 1982). Further studies using conventional and C-banding staining have detected chromosome alterations in maize callus cultures (AguiarPerecin and Fluminhan, 1992; Fluminhan, 1992; Fluminhan et al., 1996). Mitotic instability was investigated in Feulgen-stained preparations of embryogenic calli. Bridges resulting from delayed separation of sister chromatids as well as typical bridges (Figure 1a and b), broken bridges and fragments were observed. The examination of C-banded anaphases showed that sister chromatids were held together at knob sites (primary event), an observation which gives support to the hypothesis previously proposed by Lee and Phillips (1987) to explain the high frequency of knobs in chromosome arms involved in rearrangements. Also, typical bridges with and without bands corresponding to knobs were observed. These events were interpreted as evidence of the occurrence of breakage-fusion-bridge (BFB) cycles initiated by chromosome arms broken during the primary event. These cycles would be similar to the chromatid type of BFB cycle described by McClintock (1939). Additional

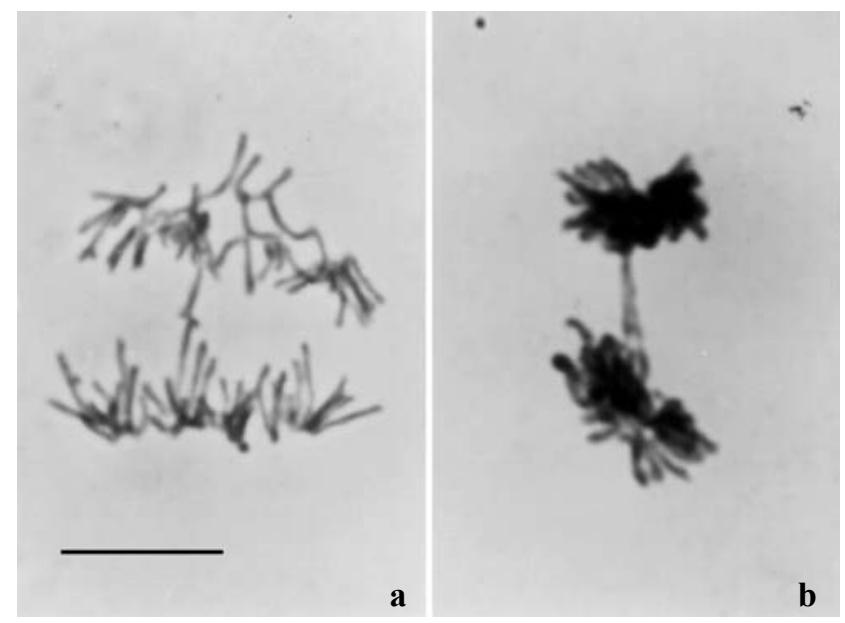

Figure 1 - Feulgen-stained anaphases of a callus culture. (a) Bridge resulting from delayed separation of sister chromatids; (b) two typical bridges, probably involved in a breakage fusion-bridge cycle. Bar $=10 \mu \mathrm{m}$. 
evidence for this mechanism was the presence of gross aberrations involving chromosome 7, interpreted as duplication-deficiencies.

Further studies involving a detailed analysis of Cbanded metaphases of 2-3-year-old cultures (Santos, 1995) and 2-4-month-old cultures (Gardingo, 1998) have provided new evidence for the occurrence of BFB cycles and have shown that chromosome 7 is the most affected. The genotypes used were lines highly related to the ones studied by Fluminhan et al. (1996). Figure 2a shows a C-banded metaphase cell with normal chromosome 7 possessing a knob on the short arm (K7S) and the long arm (K7L). Figure $2 \mathrm{~b}$ and $\mathrm{c}$ shows one of the alterations observed, that is, an amplification of $\mathrm{K} 7 \mathrm{~L}$ and if one assumes that this alteration was derived from a BFB cycle, then it must be concluded that this chromosome has a deficiency of the distal euchromatic segment (from the knob to chromosome end) on the long arm.

These observations have raised interesting questions regarding the effect of culture age on the frequency of anaphase bridges and the occurrence of chromosome healing, similar to that described by McClintock (1941, 1942, 1978b). The analysis of C-banded metaphases in 2-3-year old calli (Santos, 1995; Santos and Aguiar-Perecin, 1995) gave strong evidence for the occurrence of healing of broken chromosome ends of chromosomes 7 and 9, after BFB cycles: certain chromosome rearrangements were observed unaltered in several samples of most cultures.

Recently, Santos-Serejo, Mondin and Aguiar-Perecin found plants homozygous for an amplification at $\mathrm{K} 7 \mathrm{~L}$, in $\mathrm{R}_{1}$ progenies derived from regenerated plants heterozygous for this aberration. In this specific case, we speculate that this amplification of K7L was originated through a mechanism other than the BFB cycle. Gardingo (1998) detected the occurrence of unequal sister chromatid exchange in chromosome 7, resulting in amplification and deficiency at K7L. This event was observed in some cultures and must be another mechanism of chromosome alteration in vitro. In this case, chromosome 7 would not be deficient for the distal segment of the long arm.

Among other aspects investigated in our laboratory is that of the correlation between knob content and the frequency of anaphase bridges in callus cultures. If delayed chromatid separation is the primary event causing bridge formation, then we could expect a lower frequency of bridges in genotypes with low knob content. This was investigated using 5-6-month-old cultures derived from four families of related inbred lines differing in their knob contents (Fluminhan and Aguiar-Perecin, 1998). The lines used were homozygous for knobs at $6 \mathrm{~L}_{2}, 6 \mathrm{~L}_{3}, 7 \mathrm{~L}$ and $8 \mathrm{~L}_{1}$ and differed for the presence or absence of K2L, K3L, K7S and K9S (references in Aguiar-Perecin and Decico, 1998;

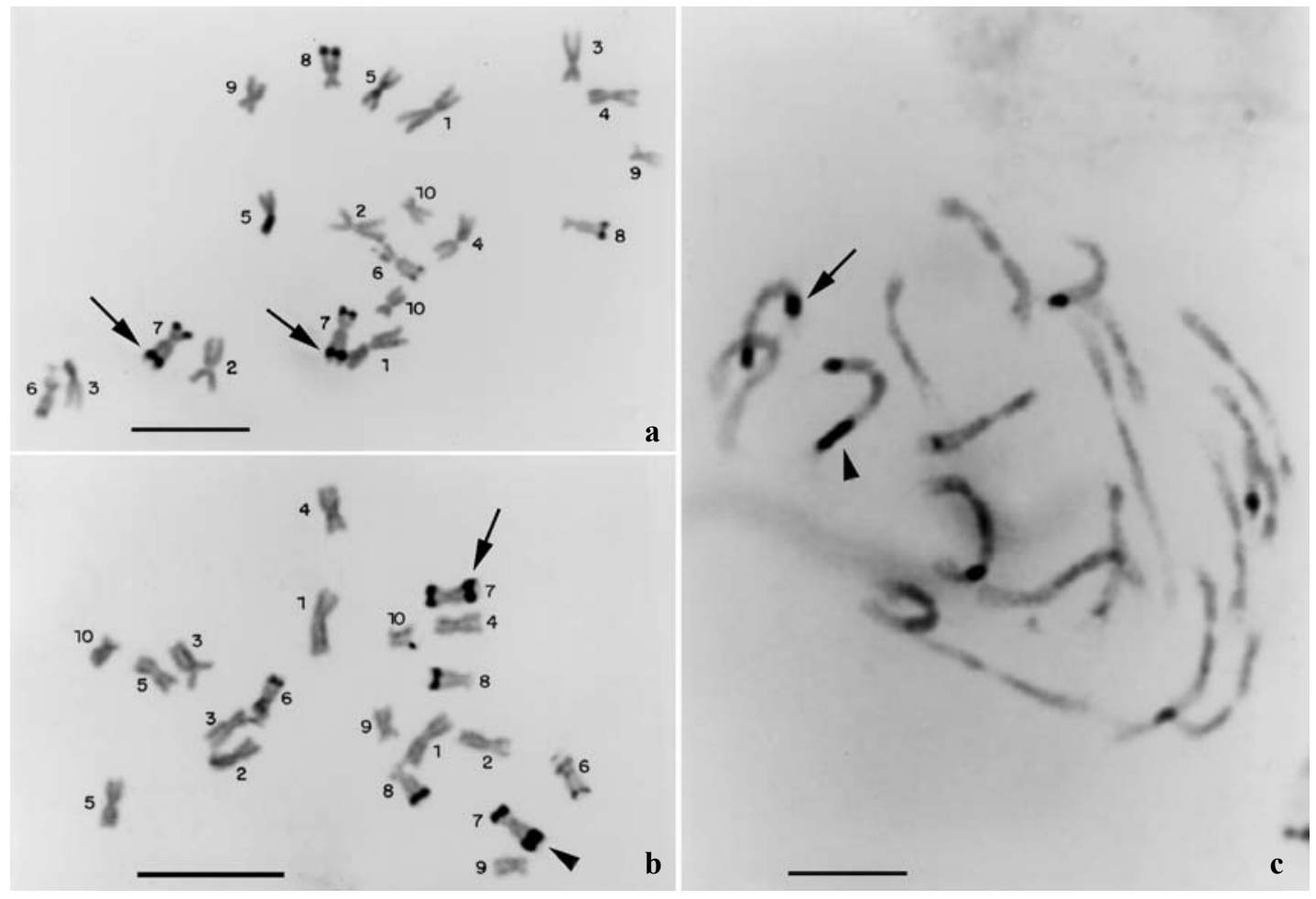

Figure 2 - C-banded mitotic cells from root tips of regenerated plants. (a,b) Metaphases from plants homozygous for normal chromosome 7 (a) and heterozygous for amplification (small arrow) of K7L (b). (c) Mitotic prophase from a plant heterozygous for K7L amplification (small arrow). Bar $=10 \mu \mathrm{m}$. 
Decico, 1991). Differences in embryogenic response were observed between these families of inbreds. Only one family formed highly embryogenic type II calli. Mitotic instability was investigated in most cultures and delayed separating chromatids, typical bridges and fragments were observed. The frequency of both types of bridges was not strictly correlated with the knob content of the genotypes analyzed, suggesting that knobs may undergo alterations leading to mitotic disturbance and that this response may be genotype dependent.

This research project represents a contribution to the study of stress caused by the tissue culture environment on chromosome behavior and response dependent on genotype and heterochromatin content, as well as provides information for the selection of genotypes yielding a high frequency of embryogenic cultures with a low level of chromosome instability (Gardingo, 1998; Santos-Serejo, 1999).

\section{ACKNOWLEDGMENTS}

\section{Publication supported by FAPESP.}

\section{REFERENCES}

Aguiar-Perecin, M.L.R. de (1985). C-banding in maize. I. Band patterns. Caryologia 38: 23-30.

Aguiar-Perecin, M.L.R. de and Decico, J.U. (1988). Preliminary results on the segregation of knobs (C-bands) in inbred lines derived from a flint variety. Maize Genet. Coop. Newsl. 62: 100.

Aguiar-Perecin, M.L.R. de and Fluminhan, A. (1992). Mitotic instability in callus cultures of inbred lines adapted to tropical regions. Maize Genet. Coop. Newsl. 66: 87-88.

Aguiar-Perecin, M.L.R. de and Vosa, C.G. (1985). C-banding in maize. II. Identification of somatic chromosomes. Heredity 54: 37-42.

Ananiev, E.V., Phillips, R.L. and Rines, H.W. (1998). Complex structure of knob DNA on maize chromosome 9: retrotransposon invasion into heterochromatin. Genetics 149: 2025-2037.

Bertão, M.R. (1998). Caracterização citogenética de linhagens de milho (Zea mays L.) através de bandamento cromossômico e hibridação molecular in situ. PhD thesis, ESALQ, Universidade de S. Paulo, Piracicaba.

Chen, C.C. (1969). The somatic chromosomes of maize. Can. J. Genet. Cytol. 11: 752-754.

Chughtai, S.R. and Steffensen, D.M. (1987). Heterochromatic knob composition of commercial inbreds of maize. Maydica 32: 171-187.

Decico, M.J.U. (1991). Análise da segregação de knobs em progênies $F_{2} e$ de retrocruzamento derivadas de uma variedade de milho. MSc thesis, ESALQ, Universidade de S. Paulo, Piracicaba.

Dennis, E.S. and Peacock, W.J. (1984). Knob heterochromatin homology in maize and its relatives. J. Mol. Evol. 20: 341-350.

Edallo, S., Zucchinali, C., Perenzin, M. and Salamini, F. (1981). Chromosomal variation and frequency of spontaneous mutation associated with in vitro culture and plant regeneration in maize. Maydica 26: 3956.

Filion, W.G. and Walden, D.B. (1973). Karyotype analysis. The detection of chromosomal alterations in the somatic karyotype of Zea mays $\mathrm{L}$. Chromosoma 41: 183-194.

Fluminhan, A. (1992) Cultivo in vitro de milho (Zea mays L.) e análise de sua instabilidade mitótica. MSc thesis, ESALQ, Universidade de S. Paulo, Piracicaba.

Fluminhan, A. and Aguiar-Perecin, M.L.R. de (1998). Embryogenic response and mitotic instability in callus cultures derived from maize inbred lines differing in heterochromatin knob content of chromosomes. Ann. Bot. 82: 569-576.

Fluminhan, A., Aguiar-Perecin, M.L.R. de and Santos, J.A. (1996). Evi- dence for heterochromatin involvement in chromosome breakage in maize callus culture. Ann. Bot. 78: 73-81.

Gardingo, J.R. (1998). Resposta embriogênica e estabilidade cromossômica em calos derivados de linhagens e híbridos de milho (Zea mays L.) $\mathrm{PhD}$ thesis, ESALQ, Universidade de S. Paulo, Piracicaba.

Hadlaczky, G.Y. and Kálmán, L. (1975). Discrimination of homologous chromosomes of maize with Giemsa staining. Heredity 35: 371-374.

Jewell, D.C. and Islam-Farid, N. (1994). A technique for somatic chromosome preparation and C-banding of maize. In: The Maize Handbook (Freeling, M. and Walbot, V., eds.). Springer-Verlag, New York, pp. 484-494.

Johnson, S.S., Phillips, R.L. and Rines, H.W. (1987). Possible role of heterochromatin in chromosome breakage induced by tissue culture in oats (Avena sativa L.) Genome 29: 439-446.

Lapitan, N.L.V., Sears, R.G. and Gill, B.S. (1984). Translocations and other karyotypic structural changes in wheat $\mathrm{x}$ rye hybrids regenerated from tissue culture. Theor. Appl. Genet. 68: 547-554.

Larkin, P.J. and Scowcroft, W.R. (1981). Somaclonal variation - a novel source of variability from cell cultures for plant improvement. Theor. Appl. Genet. 60: 197-214.

Lee, M. and Phillips, R.L. (1987). Genomic rearrangements in maize induced by tissue culture. Genome 29: 122-128.

Longley, A.E. (1938). Chromosomes of maize from North American Indians. J. Agric. Res. 56: 177-195.

McClintock, B. (1929). Chromosome morphology in Zea mays. Science 69: 629 .

McClintock, B. (1930). A cytological demonstration of the location of an interchange between two non-homologous chromosomes of Zea mays. Proc. Natl. Acad. Sci. USA 16: 791-796.

McClintock, B. (1931). Cytological observations of deficiencies involving known genes, translocations and an inversion in Zea mays. Res. Bull. Mo. Agric. Exp. Stn. 163.

McClintock, B. (1933). The association of non-homologous parts of chromosomes in the mid-prophase of meiosis in Zea mays. Z. Zellforsch. Mikrosk. Anat. 19: 191-237.

McClintock, B. (1939). The behavior in successive nuclear divisions of a chromosome broken at meiosis. Proc. Natl. Acad. Sci. USA 25: 405-416.

McClintock, B. (1941). The stability of broken ends of chromosomes in Zea mays. Genetics 26: 234-282.

McClintock, B. (1942). The fusion of broken ends of chromosomes following nuclear fusion. Proc. Natl. Acad. Sci. USA 18: 458-463.

McClintock, B. (1978a). Significance of chromosome constitutions in tracing the origin and migration of races of maize in the Americas. In: Maize Breeding and Genetics (Walden, D.B., ed.). John Wiley \& Sons, New York., pp. 159-184.

McClintock, B. (1978b). Mechanisms that rapidly reorganize the genome. Stadler Genet. Sym. 10: 25-47.

McClintock, B., Kato, Y.T.A. and Blumenschein, A. (1981). Chromosome Constitution of Races of Maize. Its Significance in the Interpretation of Relationships Between Races and Varieties in the Americas. Colegio de Posgraduados, Chapingo, Mexico.

McCoy, T.J. and Phillips, R.L. (1982). Chromosome stability in maize (Zea mays) tissue cultures and sectoring in some regenerated plants. Can. J. Genet. Cytol. 24: 559-565.

McCoy, T.J., Phillips, R.L. and Rines, H.W. (1982). Cytogenetic analysis of plants regenerated from oat (Avena sativa) tissue cultures: High frequency of partial chromosome loss. Can. J. Genet. Cytol. 24: 37-50.

Peacock, W.J., Dennis, E.S., Rhoades, M.M. and Pryor, A.J. (1981). Highly repeated DNA sequence limited to knob heterochromatin in maize. Proc. Natl. Acad. Sci. USA 78: 4490-4494.

Peschke, V.M. and Phillips, R.L. (1992). Genetic implications of somaclonal variation in plants. Adv. Genet. 30: 41-75.

Pryor, A.J., Faulkner, K., Rhoades, M.M. and Peacock, W.J. (1980). Asynchronous replication of heterochromatin in maize. Proc. Natl. Acad. Sci. USA 18:222-229.

Rayburn, A.L., Price, H.J., Smith, J.D. and Gold, J.R. (1985). C-band heterochromatin and DNA content in Zea mays. Am. J. Bot. 72: 16101617.

Rhoades, M.M. (1955). The cytogenetics of maize. In: Corn and Corn Improvement (Sprague, G.F., ed.). Academic Press, New York, pp. 123-219.

Rhoades, M.M. (1978). Genetic effects of heterochromatin in maize. In: 
Maize Breeding and Genetics (Walden, D.B., ed.). John Wiley \& Sons, New York, pp. 641-671.

Rhoades, M.M. and Dempsey, E. (1973). Chromatin elimination induced by B chromosomes of maize. J. Hered. 64: 13-18.

Sacristan, M.D. (1971). Karyotypic changes in callus cultures from haploid and diploid plants of Crepis capillaris (L) Wallr. Chromosoma 33: 273-283.

Santos, J.A. (1995). Estudo da instabilidade cromossômica em culturas de longa duração de calos de milho (Zea mays L.). MSc thesis, ESALQ, Universidade de S. Paulo, Piracicaba.

Santos, J.A. and Aguiar-Perecin, M.L.R. de (1995). Chromosome instabil- ity in long-term callus cultures. Chrom. Res. 3 (Suppl.): 60.

Santos-Serejo, J.A. (1999). Análise da transmissão e comportamento meiótico de cromossomos alterados em plantas de milho regeneradas in vitro e seleção de genótipos para culturas de calos com alta capacidade de regeneração. PhD thesis, ESALQ, Universidade de S. Paulo, Piracicaba.

Viotti, A., Privitera, E., Sala, E. and Pogna, N. (1985). Distribution and clustering of two highly repeated sequences in the A and B chromosomes of maize. Theor. Appl. Genet. 70: 234-239.

Ward, E.J. (1980). Banding patterns in maize mitotic chromosomes. Can. J. Genet. Cytol. 22: 61-67. 
